\title{
Investigating the Effect of Aspirin on Mercury Toxicity
}

\author{
Fatih Polat $^{1}$ and Tark Dal ${ }^{2}$ \\ ${ }^{1}$ Department of Environmental Protection, Almus Vocational High School, Gaziosmanpaşa University, \\ Almus, 60900 Tokat, Turkey \\ ${ }^{2}$ Department of Fisheries, Almus Vocational High School, Gaziosmanpaşa University, Almus, 60900 Tokat, Turkey
}

Correspondence should be addressed to Fatih Polat; fatih.polat@gop.edu.tr

Received 6 May 2013; Accepted 25 July 2013

Academic Editor: José Morillo

Copyright (C) 2013 F. Polat and T. Dal. This is an open access article distributed under the Creative Commons Attribution License, which permits unrestricted use, distribution, and reproduction in any medium, provided the original work is properly cited.

The effect of aspirin on the toxicology of mercury was investigated by using fish. The variations between blood parameters of the fish, which were made exposed directly to mercury solutions prepared at certain concentrations $(500 \mu \mathrm{g} / \mathrm{L}, 250 \mu \mathrm{g} / \mathrm{L}, 125 \mu \mathrm{g} / \mathrm{L}$, $62.5 \mu \mathrm{g} / \mathrm{L}$, and $31.25 \mu \mathrm{g} / \mathrm{L}$ ), and blood parameters of the fish, which were made exposed to mercury at the same concentrations after they had been interacting with aspirin, were investigated. At the end of the study, increases in blood parameters were observed depending on the increases in mercury concentration. Statistically significant variations were observed in blood parameters of the fish, which were made exposed to mercury at the same concentrations after they had been interacting with aspirin, compared to blood parameters of the fish, which were made exposed directly to mercury $(P<0.05)$. It was found that aspirin has caused significant increases in especially the levels of serum aspartate aminotransferase and alanine aminotranspherase and significant decreases in cortisol and glucose levels among to blood parameters. It was concluded that aspirin alters the toxic effect of mercury.

\section{Introduction}

Aspirin is the popular name of a salicylate ester of acetic acid. Aspirin (acetyl salicylic acid) is an anti-inflammatory medicine, which has been in the use prevalently since 1899 for rheumatic diseases because it is very effective and inexpensive. Aspirin affects antioxidant system by shifting the equilibrium between oxidants and antioxidants in favor of oxidants causing hepatic and renal damages [1]. Although many nonsteroidal anti-inflammatory drugs (NSAID) have been added to the treatment in the recent 30 years, aspirin indisputably keeps its position during treatment of rheumatic diseases like RA and Kawasaki and new areas in which it can be used like antiphospholipid antibody syndrome and Alzheimer have emerged. Aspirin is absorbed rapidly after it is dissolved and hydrolyzed in the liver, and it can be seen in plasma after 10-20 minutes. Serum reaches the peak value in two hours. Aspirin is hydrolyzed into salicylic acid by nonspecific esterases in liver and bound to salicylate serum proteins, especially albumin. Cytoplasmic enzyme (LDH) released due to salicylates without depending on dose has an effect on hepatotoxicity [2].
Many plant and animal species act as a bioindicator to observe many pollutants in the ecosystem surrounding us [38]. It is becoming more important day by day to predict and describe the hidden and harmful effects, which come into sight when that fish is exposed to low toxic matter without showing any symptom of poisoning, in toxicological studies $[9,10]$. Heavy metal deposition, which has been increasing every day, in fish has a toxic effect and furthermore, affects human health because fish represent a loop of the biological cycle and they are eaten as a significant protein resource [11]. Fish are the organisms having close relations with the environment in which they live. They can demonstrate stress resources, which might be present in the water surrounding them, ease in their bodies by a metabolic way due to the close relations between them and the water [12]. The heavy metal effect is another stress factor for fish in addition to famine, reproduction, and hypoxic conditions.

Mercury is one of the most toxic heavy metals and has been introduced into the environment in the form of inorganic and organic mercury compounds through paper industry, gold and silver mining, electricity industry, paints, fungicides, and drug industry [13]. Mercury may deposit in 
plants and animals. Furthermore, it may cause damage in the central nervous system in case of intake by the human body. Metallic mercury and organic mercury determination has come under consideration in recent years due to their tendency to deposit in aquatic organisms and human body and due to its toxicological effect. According to WHO, the allowed limit for mercury in potable water is much lower than $1 \mu \mathrm{g} / \mathrm{L}[14]$.

When an organism perceives an adverse situation as a stress resource, it gives a response to it and as a result the level of certain hormones (adrenaline, cortisol, glucose, etc.) in the blood increases [15-17]. Thus, it is possible to investigate the effects of the stress on the organism by determining blood parameters in these hormones in case of stress states. Cortisol is released from cortex layer of the adrenal gland in stress responses given to many forms of environmental stress. Cortisol may cause many physiological variations if the time during which it is released extends [18]. Glucose is the essential high-energy compound in vertebrate, and stored in muscle and liver tissues in the form of glycogen. Therefore, it is very important to determine variations especially in blood parameters of aquatic organisms under the effect of pollutants in metabolic and physiological events because they indicate the pollution level in that environment [19].

The energy required by fish is supplied by lipids and proteins, in addition to carbohydrates, mediated by gluconeogenic enzymes like aspartate aminotranspherase (AST) and alanine aminotranspherase (ALT) [20]. Aspartate aminotranspherase and alanine aminotranspherase catalyze two of the most important aminotranspherase reactions [21]. Aminotranspherases are normally intracellular enzymes. High aminotranspherase levels in plasma indicate damage in cells, which are rich in such enzymes. For example, a physical trauma or any disease causes cell destruction and thus, intracellular enzymes find their way to the blood. Two of the aminotranspherase have a diagnostic value. These are AST and ALT. High AST and ALT levels occur in plasma in almost all liver diseases [21, 22].

Salicylates may react to produce a chelate complex. In other words, they may act as a chelate producer, which can collect certain metals in the body [23]. This indicates a need for a study on whether or not aspirin causes different effects on organisms containing heavy metals.

This study was conducted to investigate how much aspirin influences toxic effects of Mercury, which is one of the most toxic heavy metals, by using certain blood parameters of fish.

\section{Material and Methods}

2.1. Reagents. Chemicals with the use pure water, which were produced by Millipore's ultrapure water device, was used during the analyses. All chemicals, which were used, are pure at analytic grade and were purchased from Merck (Darmstadt, Germany). Stock mercury solution ( $\mu \mathrm{g} / \mathrm{L})$ was prepared by using Mercury (II) chloride. Then, this stock solution was diluted to prepare standard solutions (500$31,25 \mu \mathrm{g} / \mathrm{L})$. Aspirin was used in the form of a tablet. Each tablet contains $500 \mathrm{mg}$ salicylic acid.
2.2. Investigation Media and the Processes Which Were Applied to Fish. All materials made of glass were treated with $10 \%$ $\mathrm{HNO}_{3}$ (Merck) solution, maintained in $30 \mathrm{mM} \mathrm{Na}$ EDTA (Merck) solution for a night to remove metal ions, which might have been adsorbed on their surfaces, and rinsed with ultrapure water before being used in the laboratory. The fish, Carp (Cyprinus Carpio), which was used as the material of the study, was supplied by Gaziosmanpaşa University's Almus Vocational High School, Department of Fisheries. The fishes were placed in glass aquariums, each has a volume of $40 \mathrm{~L}$ (sizes $39 \times 36 \times 28.5 \mathrm{~cm}$ ), fed regularly for a week to ensure their adaptation. The weight of the fish used in the study is $55 \mathrm{~g}$ while their length is $15 \mathrm{~cm}$. Temperature, $\mathrm{pH}$ and dissolved oxygen level of the water inside the aquariums were kept constant during the experiment. In the experiment, the aquariums were divided into two separate groups. Solutions at concentrations of 500, 250, 125, 62.5, and $31.25 \mu \mathrm{g} / \mathrm{L}$ were added to the aquariums in the first group while one of them was specified as the control. Three fish were placed in each aquarium in this group. The fish were made exposed to mercury for $48 \mathrm{hrs}$ in the aquariums. Aspirin was applied to the fish in the aquariums in the second group in the form of tablet at a dose of 1 tablet per day for 15 days $(187.5 \mathrm{mg} / \mathrm{L}$ aspirin in total was applied to each aquarium) and then, the treatments to which the fish in the first group had been exposed were repeated for the second group.

2.3. Taking Blood Samples from the Fish Samples. Blood samples were collected from the heart of the fish, which had had an impact on the head, without applying anesthesia, through the puncture. For this purpose, a $5 \mathrm{~mL}$ sterile disposable syringe with a green end was inserted at an angle of 40-45 degrees at a distance of ones third from the bottom into the heart just before the pectoral arch formed by cleithrum bone after the gill cover of the fish resting on its side had been lifted and the drawn blood was transferred into suitable test tubes $[24,25]$. Blood samples were collected from 36 fishes in total. These samples were brought to the lab under suitable storage conditions and immediately analyzed.

2.4. Analyses of Blood Parameters. Samples were placed into centrifuge tubes, which were free from any anticoagulant, and centrifuged at $3500 \mathrm{RPM}$ (cycles/minute) for 5 minutes (NF $800 \mathrm{R}$ ) to move the serum to be used in determining glucose, aspartate aminotranspherase, alanine aminotranspherase, lactate dehydrogenase, and cortisol to the upper phase. Then, glucose, aspartate aminotranspherase, alanine aminotranspherase, lactate dehydrogenase, and cortisol levels in the blood samples were read in the Cobas 6000 device with the help of on autoanalyzer by using a commercial kit in Gaziosmanpaşa University's Medical School's Biochemistry Laboratory.

2.5. Statistical Analysis. The SPSS statistics program was used to find the variations that occurred depending on varying mercury concentrations and the variations between the groups treated and not treated with aspirin. Because the data do not show a normal distribution, they were analyzed 
TABLE 1: Average values and standard deviations for blood parameters of the fish versus different mercury concentrations.

\begin{tabular}{lccccc}
\hline $\mathrm{Hg}(\mu \mathrm{g} / \mathrm{L})$ & Glucose $(\mathrm{mg} / \mathrm{L})$ & ALT $(\mathrm{U} / \mathrm{L})$ & AST $(\mathrm{U} / \mathrm{L})$ & LDH $(\mathrm{U} / \mathrm{L})$ & Cortisol (ug/dL) \\
\hline Standard & $9,67 \pm 0,57$ & $74,67 \pm 0,57$ & $2465,00 \pm 0,55$ & $3731,67 \pm 1,52$ & $0,09 \pm 0,01$ \\
500 & $779 \pm 10$ & $264,67 \pm 0,57$ & $14159,33 \pm 1,15$ & $18321,00 \pm 3,60$ & $30,37 \pm 0,05$ \\
250 & $700 \pm 00$ & $219,67 \pm 1,52$ & $6951,00 \pm 1,00$ & $16050,00 \pm 2,00$ & $27,94 \pm 0,03$ \\
125 & $54,00 \pm 1,00$ & $160,00 \pm 1$ & $6186,33 \pm 1,15$ & $9880,00 \pm 2,00$ & $17,30 \pm 0,30$ \\
62,5 & $5,00 \pm 00$ & $135,00 \pm 0$ & $5504,00 \pm 1,00$ & $7729,00 \pm 1,73$ & $16,00 \pm 1,00$ \\
31,25 & $10,33 \pm 0,57$ & $110,00 \pm 1$ & $4669,67 \pm 0,57$ & $6204,00 \pm 1,15$ & $7,65 \pm 0,01$ \\
\hline
\end{tabular}

TABLE 2: Average values and standard deviations for blood parameters of the fish exposed to aspirin and mercury.

\begin{tabular}{lccccc}
\hline & Glucose $(\mathrm{mg} / \mathrm{L})$ & ALT $(\mathrm{U} / \mathrm{L})$ & AST $(\mathrm{U} / \mathrm{L})$ & LDH $(\mathrm{U} / \mathrm{L})$ & Cortisol $(\mathrm{uL})$ \\
\hline Standard & $9,67 \pm 0,57$ & $74,67 \pm 0,57$ & $2465,00 \pm 0,55$ & $3731,67 \pm 1,52$ & $0,09 \pm 0,01$ \\
Aspirin $(\mu \mathrm{g} / \mathrm{L})$ & $4,66 \pm 0,57$ & $209,66 \pm 1,52$ & $5754,67 \pm 0,57$ & $5574,66 \pm 0,57$ & $5,10 \pm 0,10$ \\
Aspirin $+\mathrm{Hg}(500 \mu \mathrm{g} / \mathrm{L})$ & $10,00 \pm 0,00$ & $425,33 \pm 0,57$ & $18345,00 \pm 1,00$ & $15171,00 \pm 1,00$ & $29,76 \pm 0,05$ \\
Aspirin $+\mathrm{Hg}(250 \mu \mathrm{g} / \mathrm{L})$ & $9,33 \pm 1,52$ & $349,67 \pm 0,58$ & $12344,67 \pm 0,58$ & $10974,67 \pm 0,57$ & $26,7 \pm 0,43$ \\
Aspirin $+\mathrm{Hg}(125 \mu \mathrm{g} / \mathrm{L})$ & $8,33 \pm 0,58$ & $340,33 \pm 0,58$ & $11754,67 \pm 0,57$ & $10520,33 \pm 2,51$ & $10,20 \pm 0,60$ \\
Aspirin $+\mathrm{Hg}(62,5 \mu \mathrm{g} / \mathrm{L})$ & $5,00 \pm 0,00$ & $294,66 \pm 0,58$ & $10283,33 \pm 3,78$ & $10455,00 \pm 1,00$ & $7,20 \pm 0,13$ \\
Aspirin $+\mathrm{Hg}(31,25 \mu \mathrm{g} / \mathrm{L})$ & $4,66 \pm 0,57$ & $283,33 \pm 2,08$ & $8294,66 \pm 0,58$ & $10270,00 \pm 2,00$ & $5,36 \pm 0,06$ \\
\hline
\end{tabular}

by using the Kruskal-Wallis $H$ nonparametric test as an alternative to ANOVA. Mann-Whitney $U$ test was used to compare the relation between the two groups. Variations were considered as significant when the variations between the groups were $P<0.05$.

\section{Results}

Table 1 shows average values and standard deviations for blood parameters of the fish versus different mercury concentrations.

Table 2 shows average values and standard deviations for blood parameters of the fish exposed to aspirin and mercury.

Regular increases were observed, compared with the standard, in blood parameters of the fish in the first group (I), which had been directly exposed to mercury, and those of the fish in the second group (II), which had been treated with aspirin at a total concentration of $187.5 \mathrm{mg} / \mathrm{L}$ for 15 days before being exposed to mercury (Tables 1 and 2). This increase was considered as statistically significant for almost all parameters $(P<0.05)$.

In comparison of the two groups, the difference between the blood parameters was considered as statistically significant (Table 3).

Glucose and cortisol values from blood parameters of the fish taking place in Group II have decreased significantly compared with the Group I while ALT and AST values increased significantly. LDH values increased significantly compared with the Group I except the fish exposed to mercury at concentrations of $500 \mu \mathrm{g} / \mathrm{L}$ and $250 \mu \mathrm{g} / \mathrm{L}$ (Tables 1,2 , and 3 ).

\section{Discussion}

Aspirin is prevalently used by people, who are healthy and suffer from cardiovascular disease risk, to decrease blood
TABLE 3: $P$ values between blood parameters of the fish taking place in ${ }^{a}$ (the group exposed to mrcury) and ${ }^{b}$ (the group exposed to aspirin and mercury).

\begin{tabular}{lccccc}
\hline $\mathrm{Hg}(\mu \mathrm{g} / \mathrm{L})$ & Glucose & ALT & AST & LDH & Cortisol \\
\hline 500 & 0,037 & 0,043 & 0,046 & 0,05 & 0,05 \\
250 & 0,037 & 0,046 & 0,046 & 0,046 & 0,05 \\
125 & 0,046 & 0,046 & 0,043 & 0,05 & 0,05 \\
62,5 & 1 & 0,034 & 0,05 & 0,046 & 0,05 \\
31,25 & 0,43 & 0,05 & 0,043 & 0,043 & 0,046 \\
\hline
\end{tabular}

${ }^{\mathrm{a}}$ I. Grup: The Grup exposed to mercury.

${ }^{b}$ II. Grup: The Grup exposed to aspirin and mercury.

viscosity and due to its antithrombotic effect [26-29]. Like all other medicines, aspirin has side effects besides its healing effect. The dose, which will cause hematological side effect, is not known for aspirin. Aspirin inhibits thrombocyte aggregation and extends the bleeding time. Cytoplasmic enzyme (LDH) released due to salicylates without depending on dose has an effect on hepatotoxicity [2]. Such side effects of aspirin should be taken under consideration beside its acceptable benefits by everybody. Salicylates may react to produce a chelate complex. In other words, they may act as a chelate producer, which can collect certain metals in the body [23]. This indicates a need for a study on whether or not aspirin causes different effects on organisms containing heavy metals. This study was conducted to investigate how much aspirin influences toxic effects of mercury, which is one of the most toxic heavy metals by using certain blood parameters of fish. Former studies realized successfully on the determination of mercury in Marine Fish Species [30, 31]. Besides, various studies are available and were conducted on aspirin and blood parameters by using test animals. Nergiz (1985) [32] investigated alterations caused by aspirin in liver of white mice. Durgun et al., (1998) [26] studied effects of 
aspirin on certain blood parameters in rabbits fed by highcholesterol ration in their study. Çam (2007) [33] investigated blood parameter levels to examine the activity of phenethyl ester of caffeic acid in mice stimulated by aspirin in this study. In our study, effect of mercury in fish stimulated by aspirin was investigated by examining blood parameters. Metals freed in aquatic media cause certain disorders in fish and affect their blood parameters also [34]. Studies are available in the literature evidencing effects of certain metals on blood parameters of fish. It was determined that metal effect in the fish increases the release of stress hormones like cortisol, epinephrine, and catecholamine to cause changes in carbohydrate metabolism [35, 36]. Metals like copper, chromium, nickel, and cadmium as well as chelate complexes play a role in inducing carcinogenesis during and after lipid peroxidation [37]. Hilmy et al., (1985) [38] determined that serum AST and ALT levels increased under metallic effect at the beginning in Cyprinus carpio made exposed to effect of cadmium at different concentrations for 30 days and they decreased upon extension of exposure time. It was reported in some studies that increases were observed in plasma cortisol, glucose and lactate levels in different fish species exposed to stressors like heavy metals [39-43]. In our study also, increases were observed in glucose, AST, ALT, LDH and cortisol levels, compared with the standard, in the blood of the fish exposed to mercury (Table 1). The differences were found statistically significant for all parameters (except the values corresponding to mercury concentrations of $31.25 \mu \mathrm{g} / \mathrm{L}$ and $62.50 \mu \mathrm{g} / \mathrm{L}$ for glucose) at all concentrations $(P<0.05)$. It is reported in the literature that the equilibrium between oxidants and antioxidants is shifted by aspirin in favor of oxidants to cause damage on antioxidant system and thus, eventually, may cause injuries in liver and kidneys. It is also reported in the literature that an increase in ALT value may indicate damage in liver [1]. It was found in our study that aspirin caused an increase in all blood parameters compared to the standard except for glucose. Erdem and coworkers studied selenium's and zinc's protective effect against damage, which might be caused by aspirin in the body, in 2006. It was found as a result of the study that selenium and zinc play a protective role against the damage caused by aspirin in the antioxidant system. What makes our study distinguished from other studies in the literature is the fact that our study aimed to find what type of changes aspirin causes in blood parameters of the body of an organism containing a very toxic matter like mercury at certain doses. For this purpose, the two groups were compared with each other and the variation between blood parameters was found statistically significant (Table 3). Glucose cortisol values of blood parameters of the fish taking place in Group II have decreased significantly compared with the group I while ALT, and AST, values increased significantly. LDH values increased significantly compared with the fish in Group I except the fish exposed to mercury at concentrations of $500 \mu \mathrm{g} / \mathrm{L}$ and $250 \mu \mathrm{g} / \mathrm{L}$ (Tables 1, 2, and 3). It was reported in the literature that an increase was observed in plasma AST and ALT levels in almost all liver diseases $[21,22]$. According to our findings, it may be concluded that aspirin may increase ALT and AST and LDH values to promote liver diseases in the body of an organism if the organism contains a toxic matter like mercury. Dange (1986) [44], and Karataş et al. (2005) [45] determined that stress conditions raise serum glucose and cortisol levels and if the conditions are maintained, they significantly reduce glycogen in liver to cause certain changes in carbohydrate metabolism in their study conducted on various fish species under effect of organic and inorganic pollutants. Chun and Oh (1989) [46] evidenced in a study conducted with Cyprinus carpio that serum glucose concentration is completely related to water quality and the stress caused by pollution in fish has an effect on glucose concentration. Heath (1995) [47] reported that pollution causes stress in fish and other mechanisms, which are responsible for mobilization of energy resources, are activated in case of long-term stress conditions. He also reported that one of these mechanisms is cortisol released by the adrenal cortex, cortisol acts in glycogen storage in liver by reducing the use of glucose by tissues and it keeps blood glucose at high concentrations. According to the existing studies, glucose and cortisol change depending on each other and an increase or a decrease in cortisol is determinative for glucose level in blood. In our study, it was found that cortisol and glucose changed constantly depending on each other and cortisol and glucose values were lower in the fish pretreated with aspirin compared with those made exposed to mercury directly. The degree of the decrease between these two groups was found statistically significant $(P<0.05)$. According to these results, it may be concluded that aspirin may reduce cortisol, which is caused by a toxic material like mercury and causes stress on the fish.

In our study, unlike other studies in the literature, it was found what type of changes Aspirin causes in blood parameters of the body of an organism containing a very toxic matter like mercury at certain doses. According to our findings, as the mercury concentration increases in fish, glucose, AST, ALT, LDH, and cortisol, which are some of blood parameters, increase and the increases are statistically significant. Furthermore, it was concluded that aspirin may increase ALT, and AST, and LDH values to promote liver diseases in the body of an organism if the organism contains a toxic matter like mercury; however, it may reduce the effect of mercury with respect to cortisol.

As a result of the study, it was concluded that aspirin should be used in a more controlled way in the presence of toxic heavy metals like mercury, which might exist in an organism in trace amounts.

\section{Glossary}

$\begin{array}{ll}\text { NSAID: } & \text { Nonsteroidal anti-inflammatory drugs } \\ \text { AST: } & \text { Aspartate aminotranspherase } \\ \text { ALT: } & \text { Alanine aminotranspherase. }\end{array}$

\section{Acknowledgments}

This study was conducted with the facilities of Gaziosmanpaşa University's Almus Vocational High School's Aquarium Unit and Gaziosmanpaşa University's Medical School's 
Biochemistry Laboratory. The authors would like to acknowledge them for their material support.

\section{References}

[1] O. Erdem, A. Aydın, A. Sayal, A. Cemal, V. Kesik, and A. E. Kurekçi, "In vivo investigation of efficiency and preventive role of selenium and zinc on aspirin induced impairment on antioxidant system, hepatic and renal toxicity," Toxicology Letters, vol. 164, p. 131, 2006.

[2] F. S. Tunaoğlu, "The use of Aspirin and childhood rheumatic diseases," Klinik Pediatrik, vol. 1, pp. 26-34, 2002.

[3] M. S. Astorga-España, E. M. Peña-Méndez, and F. J. GarcíaMontelongo, "Application of principal component analysis to the study of major cations and trace metals in fish from Tenerife (Canary Islands)," Chemometrics and Intelligent Laboratory Systems, vol. 49, no. 2, pp. 173-178, 1999.

[4] B. P. Cid, C. Boia, L. Pombo, and E. Rebelo, "Determination of trace metals in fish species of the Ria de Aveiro (Portugal) by electrothermal atomic absorption spectrometry," Food Chemistry, vol. 75, no. 1, pp. 93-100, 2001.

[5] J. A. Baig, T. G. Kazi, M. B. Arain et al., "Arsenic fractionation in sediments of different origins using BCR sequential and single extraction methods," Journal of Hazardous Materials, vol. 167, no. 1-3, pp. 745-751, 2009.

[6] O. D. Uluozlu, M. Tuzen, and M. Soylak, "Speciation and separation of $\mathrm{Cr}(\mathrm{VI})$ and $\mathrm{Cr}(\mathrm{III})$ using coprecipitation with $\mathrm{Ni}^{2+}$ /2-Nitroso-1-naphthol-4-sulfonic acid and determination by FAAS in water and food samples," Food and Chemical Toxicology, vol. 47, no. 10, pp. 2601-2605, 2009.

[7] S. Sounderajan, G. K. Kumar, and A. C. Udas, "Cloud point extraction and electrothermal atomic absorption spectrometry of Se (IV)-3, $3^{\prime}$-diaminobenzidine for the estimation of trace amounts of Se (IV) and Se (VI) in environmental water samples and total selenium in animal blood and fish tissue samples," Journal of Hazardous Materials, vol. 175, no. 1-3, pp. 666-672, 2010.

[8] D. Mendil, O. F. Ünal, M. Tüzen, and M. Soylak, "Determination of trace metals in different fish species and sediments from the River Yeşilırmak in Tokat, Turkey," Food and Chemical Toxicolojy, vol. 48, pp. 1383-1392, 2010.

[9] S. Katalay and H. Parlak, "The effects of water pollution on blood parameters of Gobius niger Linn. 1758 (Pisces Gobiidae)," Journal of Fisheries and Aquatic Sciences, vol. 19, pp. 115-121, 2002.

[10] A. Larsson, C. Haux, and M.-L. Sjobeck, "Fish physiology and metal pollution: results and experiences from laboratory and field studies," Ecotoxicology and Environmental Safety, vol. 9, no. 3, pp. 250-281, 1985.

[11] I. Kir and H. Tumantozlu, "Investigation of some heavy metal accumulation in water, sediment and carp (Cyprinus carpio) samples of Karacaoren-II Dam Lake," Ekoloji, no. 82, pp. 65-70, 2012.

[12] I. Cengizler, Fish Diseases, Çukurova University Faculty of Aquaculture Issues, Adana, Turkey, 2000.

[13] A. Niazi, T. Momeni-Isfahani, and Z. Ahmari, "Spectrophotometric determination of mercury in water samples after cloud point extraction using nonionic surfactant Triton X-114," Journal of Hazardous Materials, vol. 165, no. 1-3, pp. 1200-1203, 2009.

[14] A. Hamza, A. S. Bashammakh, A. A. Al-Sibaai, H. M. AlSaidi, and M. S. El-Shahawi, "Part 1. Spectrophotometric determination of trace mercury (II) in dental-unit wastewater and fertilizer samples using the novel reagent 6-hydroxy-3-(2oxoindolin-3-ylideneamino)-2-thioxo-2H-1,3-thiazin-4(3H)one and the dual-wavelength $\beta$-correction spectrophotometry," Journal of Hazardous Materials, vol. 178, no. 1-3, pp. 287-292, 2010.

[15] A. Soivio, K. Nynolm, and K. Westman, "A technique for repeated sampling of the blood of individual resting fish," Journal of Experimental Biology, vol. 63, no. 1, pp. 207-217, 1975.

[16] A. Soivio, K. Westman, and K. Nyholm, "Changes in haematocrit values in blood samples treated with and without oxygen: a comparative study with four salmonid species," Journal of Fish Biology, vol. 6, no. 6, pp. 763-769, 1974.

[17] A. Soivio and A. Oikari, "Haematological effects of stress on a teleost, Esox lucius L.," Journal of Fish Biology, vol. 8, no. 5, pp. 397-411, 1976.

[18] A. Yıldırım, Pollutants upon the Effects of Blood Paramaters on Carps Living in Yeşilırmak River, Gaziosmanpaşa Universty, Graduate School of Natural and Applied Sciences, Department of Fisheres and Aquaculture, Tokat, Turkey, 2010.

[19] M. E. Özaslan, Determınatıon of sera glucose, electrolıte, hematocrite and some blood parameters of clarias gariepinus from Drainage Channels of Lower Seyhan Plains [M.S. thesis], University of Çukurova, Biology Department, Adana, Turkey, 2008.

[20] H. M. Levesque, T. W. Moon, P. G. C. Campbell, and A. Hontela, "Seasonal variation in carbohydrate and lipid metabolism of yellow perch (Perca flavescens) chronically exposed to metals in the field," Aquatic Toxicology, vol. 60, no. 3-4, pp. 257-267, 2002.

[21] P. C. Champe, A. Richard, and J. B. Harvey, Biochemistry, J.B. Lippincott, New York, NY, USA, 1994.

[22] Deutsce Gesellschaft für Klinische Chemie (DGKC), Journal of Clinical Chemistry and Clinical Biochemistry, vol. 10, pp. 182193, 1972.

[23] X. Wang, "A chelate theory for the mechanism of action of aspirin-like drugs," Medical Hypotheses, vol. 50, no. 3, pp. 239251, 1998

[24] M. Kocabatmaz and G. Ekingen, "Different types of fish, the blood sample is taken and the standardization of hematological methods," 1982, TÜBİTAK, VHAG Project No: 557, 73.

[25] A. K. Siwicki and D. P. Anderson, "Immunostimulation in fish: measuring the effects of stimulants by serological and immunological methods," in Proceedings of the Nordic Symposium on Fish Immunology, pp. 19-22, Lysekil, Sweden, 1993.

[26] Z. Durgun, E. Keskin, N. Dönmez, and F. Onder, "Effects of garlic and aspirin on some blood parameters of New Zeland rabbits fed cholesterol rich ration," Veteriner Bilimleri Dergisi, vol. 14, pp. 5-8, 1998.

[27] R. Apitz-Castro, E. Ledezma, J. Escalante et al., "Reversible prevention of platelet activation by (E,Z)-4,5,9-trithiadodeca1,6,11-triene 9-oxide (ajoene) in dogs under extracorporeal circulation," Arzneimittel-Forschung, vol. 38, no. 7, pp. 901-904, 1988.

[28] A. N. Makheja and J. M. Bailey, "Antiplatelet constituents of garlic and onion," Agents and Actions, vol. 29, no. 3-4, pp. 360363, 1990.

[29] E. Block, "The chemistry of garlic and onions," Scientific American, vol. 25, pp. 94-99, 1985.

[30] A. Q. Shah, T. G. Kazi, M. B. Arain et al., "Optimization of ultrasonic-assisted acid extraction of mercury in muscle tissues of fishes using multivariate strategy," Journal of AOAC International, vol. 92, no. 5, pp. 1580-1586, 2009. 
[31] A. Q. Shah, T. G. Kazi, J. A. Baig et al., "Determination of total mercury in muscle tissues of marine fish species by ultrasonic assisted extraction followed by cold vapor atomic absorption spectrometry," Pakistan Journal of Analytical \& Environmental Chemistry, vol. 11, pp. 12-17, 2010.

[32] Y. Nergiz, "An experimental investigation of histopathological changes seen in the liver of rats administered aspirin in various dosage and duration," Dicle Üniversitesi Tip Fakültesi Dergisi, vol. 12, pp. 161-169, 1985.

[33] H. Çam, The Efficiency of capheic acid phenethyl es ter on prevention of aspirin induced gastritis in rats [Specialty thesis], University of Süleyman Demirel upon Internal Medicine Department, Isparta, Turkey, 2007.

[34] R. Sehgal and A. B. Saxena, "Toxicity of zinc to a viviparous fish, Lebistes reticulatus (Peters)," Bulletin of Environmental Contamination and Toxicology, vol. 36, no. 1, pp. 888-894, 1986.

[35] K. V. Sastry and S. K. Subhadra Km., "In vivo effects of cadmium on some enzyme activities in tissues of the freshwater catfish, Heteropneustes fossilis," Environmental Research, vol. 36, no. 1, pp. 32-45, 1985.

[36] M. Z. Vosyliene, "The effect of heavy metal on hematological indices," Acta Zoologica Litvanica Hydrobiologia, vol. 9, pp. 7682, 1999.

[37] A. Valavanidis, T. Vlahogianni, M. Dassenakis, and M. Scoullos, "Molecular biomarkers of oxidative stress in aquatic organisms in relation to toxic environmental pollutants," Ecotoxicology and Environmental Safety, vol. 64, no. 2, pp. 178-189, 2006.

[38] A. M. Hilmy, M. B. Shabana, and A. Y. Daabees, "Effects of cadmium toxicity upon the in vivo and in vitro activity of proteins and five enzymes in blood serum and tissue homogenates of Mugil cephalus," Comparative Biochemistry and Physiology C, vol. 81, no. 1, pp. 145-153, 1985.

[39] M. V. Malhilakath, C. Pereira, E. G. Grau, and G. K. Iwama, "Metabolic responses associated with confinement stress in tilapia: the role of cortisol," Comparative Biochemistry and Physiology C, vol. 1, pp. 89-95, 1997.

[40] L. Acerete, J. C. Balasch, E. Espinosa, A. Josa, and L. Tort, "Physiological responses in Eurasian perch (Perca fluviatilis, L.) subjected to stress by transport and handling," Aquaculture, vol. 237, no. 1-4, pp. 167-178, 2004.

[41] B. C. Small, "Effect of isoeugenol sedation on plasma cortisol, glucose, and lactate dynamics in channel catfish Ictalurus punctatus exposed to three stressors," Aquaculture, vol. 238, no. 1-4, pp. 469-481, 2004.

[42] A. K. Biswas, M. Seoka, K. Takii, M. Maita, and H. Kumai, "Stress response of red sea bream Pagrus major to acute handling and chronic photoperiod manipulation," Aquaculture, vol. 252, no. 2-4, pp. 566-572, 2005.

[43] A. E. Dönmez, M. Kalay, F. Özkan, and C. E. Koyuncu, "The variations in the some blood parameters caused by therapeutic concentration of FMC and malachite green in Oreochromis niloticus (L., 1758)," Ege University Journal of Fisheries and Aquatic Sciences, vol. 23, pp. 61-64, 2006.

[44] A. D. Dange, "Changes in carbohydrate metabolism in tilapia oreochromis mossambicus, during short-term exposure to different types of pollutants," Environmental Pollution A, vol. 41, no. 2, pp. 165-177, 1986.

[45] S. Karataş, C. Erdem, and B. Cicik, "Effects of cadmium on levels of sera aspartate aminotransferase alanine aminotransferase and glucose in Cyprinus carpio (L. 1758)," Ekoloji, vol. 14, pp. 18-23, 2005.
[46] S. Chun and M. Oh, "Health assesestment by hematological studies and blood chemistries," University of Pusan Upon Institute of Marine Sciences, vol. 21, pp. 205-215, 1989.

[47] A. G. Heath, Water Pollution and Fish Physiology, CRC Press, New York, NY, USA, 1995. 

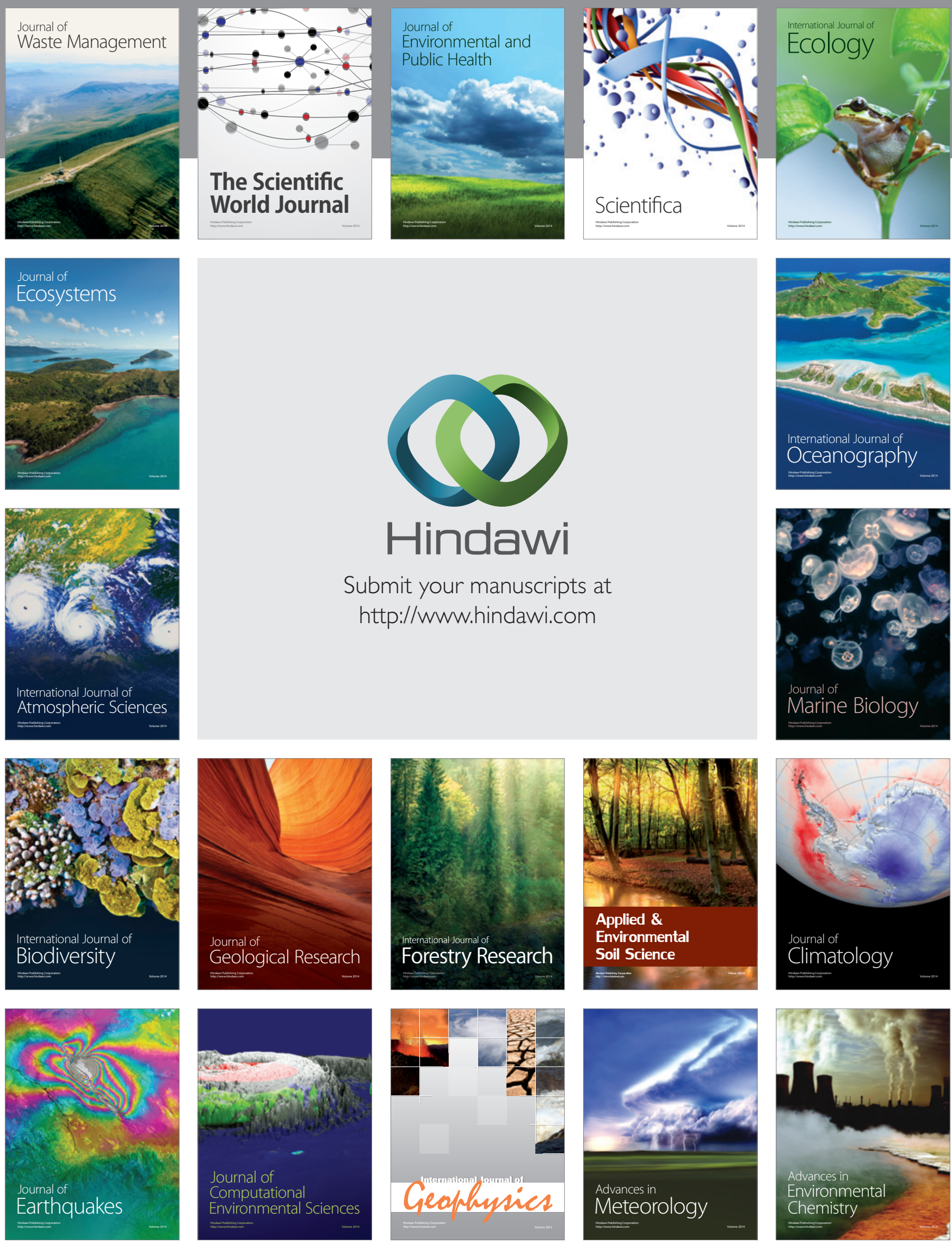